\title{
Parents' Report of Their Children's Underinsurance Status After the Affordable Care Act
}

\author{
John M. Pascoe, MD, MPH, Adrienne Stolfi, PhD, Gregory Eberhart, MD, and \\ Harry Khamis, PhD
}

Objective: To determine the prevalence and correlates of children's underinsurance pre- and postimplementation of the Affordable Care Act (ACA).

Study Design: A cross-sectional survey of a convenience sample of 5043 parents of children greater than 6 months old who had health insurance in the previous 12 months. Respondents completed the Medical Expenses for Children Survey. Pre-ACA data were collected in summer/fall of 2009 to 2011 $(n=3966)$; post-ACA data were collected in summer/fall $2016(n=1077)$. All data were collected within the Southwestern Ohio Ambulatory Research Network (SOAR-Net).

Results: Some study parents (16.3\%) were unable to follow at least 1 recommendation of their child's pediatrician due to their inability to pay for it, and $17.3 \%$ reported it had become more difficult to obtain "needed health care" in the past 3 years. Factors associated with underinsurance after adjusting for demographic factors did NOT include pre/post-ACA, but did include annual household income $<\$ \mathbf{5 0 , 0 0 0}$ (adjusted odds ratio $[\mathrm{AOR}]=2.71 ; 95 \% \mathrm{CI}, 2.15-3.40)$. Poor child health was also a significant risk factor for underinsurance(AOR $=3.71 ; 95 \% \mathrm{CI}, 2.61-5.29)$.

Conclusions: About 1 in 6 study children were underinsured. The ACA did not affect the underinsurance rate. Parents continued to report that it had become more difficult to obtain needed health care over the past 3 years post-ACA. About one third of study parents consistently reported that the health of their underinsured child had suffered because they could not afford to pay for their child's health care. (J Am Board Fam Med 2021;34:208-215.)

Keywords: Access to Health Care, Affordable Care Act, Child Health, Cross-Sectional Studies, Insurance Coverage, Ohio, Medically Uninsured, Surveys and Questionnaires

\section{Introduction}

Health insurance plays a major role in children's health care and health outcomes ${ }^{1}$ and passage of the Patient Protection and Affordable Care Act (ACA) presented this country with an opportunity to expand primary and preventive child health services. ${ }^{2}$ In 2009 about $10 \%$ of the United States' children were without health insurance ${ }^{3}$ and an even higher percentage of US children were underinsured. In a recent analysis of national data, the rate of uninsured children who were not from poor families was stable at around $4 \%$ while the uninsured rate for poor and near poor

This article was externally peer reviewed.

From the Department of Pediatrics, Wright State University-Boonshoft School of Medicine, Dayton, OH.

Funding: None.

Conflict of interest: None.

Corresponding author: John M. Pascoe, MD, MPH, Wright State University, Department of Pediatrics, One Children's Plaza, Dayton, OH 45404 (E-mail: susan. howard@wright.edu). children was closer to $6 \% .^{4}$ Meanwhile, the most recently published rate of underinsured children in the United States was $22.7 \%{ }^{5}$ in 2009 . Individuals are said to be underinsured when their health insurance requires excessive out-of-pocket expenditures, when health care services have significant coverage limitations, or when insurance fails to cover the health care expenses that are perceived by the insured person to be essential for his or her health. ${ }^{6}$

In 2011, before the ACA, there was some optimism that the ACA might reduce underinsurance in adults. ${ }^{7}$ However, recent survey data from the Commonwealth Fund indicate that while the percentage of uninsured adults has decreased post-ACA (from $20 \%$ in $2010 \%$ to $12 \%$ in 2016 and 2018), the percentage of underinsured adults has increased from $37 \%$ in 2010 , pre-ACA to $44 \%$ in $2018 .^{8}$

Many studies report high rates of underinsurance, but the lack of a consistent definition makes drawing conclusions from the results difficult. 
Some investigators define underinsurance in terms of finances (eg, percentage of income spent on health care costs $)^{9,10}$ while others describe underinsurance from the perspective of individuals' satisfaction (or dissatisfaction) with their present health insurance. ${ }^{9}$ A widely accepted definition, and the one used for this study, identifies underinsured children as those children who live in families who cannot afford clinician-recommended health care despite having insurance coverage for their children. ${ }^{11,12}$ Nearly $40 \%$ of the cost of child medical care is paid out of pocket; ${ }^{13}$ and while the problem of underinsurance in adults is well documented as noted above, studies on underinsurance of children have typically focused on children with special health care needs. ${ }^{9,14}$

Compared with children who are NOT underinsured, underinsured children are more likely to lack a medical home. Their parents report that they are unable to pay deductibles or copays, and this often results in delays in seeking recommended care and referrals. In addition, parents who postponed or went without medical care for their children reported significantly increased levels of stress, loss of time at work and other important life activities, and disability that resulted in significant pain and suffering. ${ }^{12}$

Voorhees et $\mathrm{al}^{11}$ conducted the Medical Expenses Survey in 37 primary care practices from 3 Colorado practice-based research networks. Over 1100 adults completed the survey. About one third of the study sample of adults was identified as underinsured. Those respondents reported that despite having insurance, they were unable to afford health care recommended by their provider. Another study of adults in New Mexico used a similar definition of underinsurance, and reported an underinsurance rate of $44 \% .{ }^{15}$ This study extends the examination of childhood underinsurance from a published pre ACA data set $^{16}$ to an analysis of childhood underinsurance pre- and post-ACA. The article aims to examine whether the ACA affected childhood underinsurance in southwestern Ohio and describes the prevalence and correlates of childhood underinsurance among families with children under 19 years old between 2009 and 2016.

\section{Patients and Methods \\ Materials}

The Medical Expenses for Children Survey used in this study was adapted from Voorhees' Medical
Expenses Survey, ${ }^{11}$ which had face validity confirmed by members of the High Plains Research Network Community Council. The questionnaire was revised to collect information from parents about their child. The Voorhees ${ }^{11}$ study asked 7 questions to determine whether respondents were underinsured. The colonoscopy screening question was omitted because it was inappropriate for children. The other 6 questions were included in this study. To determine underinsurance status parents were asked if, in the past 12 months, due to inability to pay: they delayed care for their child or they were unable to obtain any of the following services recommended for their child by a clinician: make or keep an appointment; fill a prescription; see a specialist; get a test; or receive other medical care. Responses to these questions (yes, no, and do not know) were identical to those employed in the Colorado study. A "yes" response to 1 or more of these questions resulted in the child being classified as "underinsured." The survey included questions regarding their child's health insurance coverage over the previous 12 months and who pays for their insurance (ie, private or government). In addition, parents were queried regarding their child's health status, whether their child's health had suffered because of not being able to afford the cost of needed care, and the ability of obtaining medical care compared with 3 years earlier. The study was approved by the Wright State University Institutional Review Board.

\section{Study Sites}

The Southwestern Ohio Ambulatory Research Network (SOAR-Net) was created in 2002 and now includes 60 primary care clinicians (the majority are general pediatricians and pediatric nurse practitioners) from 14 practices located in geographically and economically diverse areas of Dayton and the Miami Valley, including Springfield, Ohio. This study was conducted at 13 SOAR-Net practices. The military site at Wright-Patterson Air Force Base did not participate.

\section{Methods}

All participating sites agreed to at least 1 week of recruitment time when research assistants would be in their waiting rooms asking parents/caregivers to complete the anonymous Medical Expenses for Children Survey. Participants were eligible if they accompanied a patient between the ages of 6 
months old and 18 years old for an office visit. All eligible study candidates were approached in the waiting room during the 1 or 2 weeks that research assistants were collecting data at participating practices within SOAR-Net. Respondents included foster parents, adoptive parents, and birth parents. Following a brief pilot study using 30 questionnaires to confirm that the questionnaire was easy for parents/guardians to complete in their child's doctor's office, study data collection was initiated in 2009. The identical questionnaire was employed throughout the study duration. The pre-ACA data were collected summer/fall 2009 to 2011, the postACA data were collected summer/fall 2016. Completed questionnaires were returned to either the research assistant or an office receptionist. Respondents completed 5043 questionnaires. The response rate was about $90 \%$. All study parents in the analysis reported that their child had health insurance in the past 12 months.

Descriptive statistics included frequencies (percent of nonmissing data) for categorical variables and mean (SD) for continuous variables. Univariate analyses including chi-squared and 2-sample $t$-test were conducted to determine unadjusted associations between independent variables and underinsurance outcomes. Variables that were associated with underinsurance outcomes were then entered into multiple logistic analyses to determine adjusted odds ratios and 95\% CIs for associations with underinsurance outcomes, including the "time" variable pre/post-ACA. Statistical analyses were conducted using SPSS v.25 for Windows (IBM Corporation, Armonk, NY). $P<.05$ was considered statistically significant.

\section{Results}

The mean age of all study children was 6.8 years (SD, 5.0), and the mean age of parents was 34.5 years (SD, 8.1 years). About half $(52.6 \%)$ of the sample children were male. The parent who completed the questionnaire was usually the mother (85.8\%). The majority of parents $(69.9 \%)$ were either married or living as a couple. Sample parents were $83.3 \%$ White and $16.7 \%$ African American or "other race." The reported annual income for about one half of study families was less than $\$ 50,000$. About $60 \%$ of study children were covered by private health insurance in the previous year. Eightytwo percent of children were reported to have excellent or very good health status (Table 1).
Children were classified as underinsured if parents reported that their child was unable to receive needed medical care based on a "yes" response to 1 or more of the 6 questions noted in the Methods section (eg, to fill a prescription or get a test); $16.3 \%$ of study children were underinsured. Table 2 provides a summary of adjusted odds ratios that identify risk factors for childhood underinsurance. Odds ratios in Table 2 were adjusted for all the variables included in the table. Time (ie, pre/post-ACA) was NOT associated with childhood underinsurance. Mothers were more likely to report their child was underinsured compared with fathers (almost two thirds of study fathers were in the higher income subgroup compared with about one half of study mothers $P \leq$.001). For the entire study sample, parents with less income and less education were more likely to report underinsurance for their child. This may be due to the high rate of underinsurance in the subgroup of children from lower income families with private insurance. A more detailed analysis of income by insurance type (not included in a table) revealed that in households with annual income of $\$ 15,000$ to $\$ 34,999$ and private insurance, $36 \%$ of parents reported their child was underinsured compared with $22 \%(P=.002)$ of those with public insurance. Public insurance was NOT associated with underinsurance for low-income families. Children with poorer health were more likely to be underinsured compared with children with better health. In fact, there is an underinsurance gradient related to parents' report of their child's health. Compared with children with excellent health, children with fair-to-poor health have the highest odds of being underinsured while children with good-to-very-good health have intermediate odds after adjusting for a number of demographic variables (Table 2). There were 2 notable changes in correlates of childhood underinsurance pre- and post-ACA. Lower parent education was associated with higher levels of underinsurance pre-ACA compared with post-ACA and children's health being very good was also associated with underinsurance pre-ACA compared with rate of underinsurance for children with excellent health. Post-ACA children with either very good or excellent health had similar rates of underinsurance.

Two other questions addressed parents' perception of their ability to obtain medical care for their child. There was no statistically significant difference in response to those questions pre-post-ACA. Therefore, when all study parents were asked to 
Table 1. Characteristics of the Study Children and Parents

\begin{tabular}{|c|c|c|c|c|}
\hline Variable/Level & $\begin{array}{l}\text { All Parents } \\
\text { No. }(\%)\end{array}$ & $\begin{array}{c}\text { Pre-ACA } \\
\text { No. }(\%)\end{array}$ & $\begin{array}{c}\text { Post-ACA } \\
\text { No. (\%) }\end{array}$ & $P$ Value \\
\hline \multicolumn{5}{|l|}{ Underinsured $(\mathrm{n}=5043)$} \\
\hline No & $4219(83.7)$ & $3297(83.1)$ & $922(85.6)$ & \multirow[t]{2}{*}{.051} \\
\hline Yes & $824(16.3)$ & $669(16.9)$ & $155(14.4)$ & \\
\hline \multicolumn{5}{|l|}{ Parent $(n=5043)$} \\
\hline Mother & $4325(85.8)$ & $3454(87.1)$ & $871(80.9)$ & \multirow[t]{2}{*}{$<.001$} \\
\hline Father & $718(14.2)$ & $512(12.9)$ & $206(19.1)$ & \\
\hline \multicolumn{5}{|l|}{ Parent education $(\mathrm{n}=5025)$} \\
\hline$\leq \mathrm{AA} /$ some college & $3309(65.9)$ & $2661(67.4)$ & $648(60.3)$ & \multirow[t]{2}{*}{$<.001$} \\
\hline$\geq$ College grad & $1716(34.1)$ & $1289(32.6)$ & $427(39.7)$ & \\
\hline \multicolumn{5}{|l|}{ Household income $(n=4957)$} \\
\hline$<\$ 50,000$ & $2572(51.9)$ & $2095(53.6)$ & $477(45.5)$ & \multirow[t]{2}{*}{$<.001$} \\
\hline$\geq \$ 50,000$ & $2385(48.1)$ & $1814(46.4)$ & $571(54.5)$ & \\
\hline \multicolumn{5}{|l|}{ Parent race $(n=4990)$} \\
\hline Black/other & $835(16.7)$ & $649(16.6)$ & $186(17.3)$ & \multirow[t]{2}{*}{.573} \\
\hline White & $4155(83.3)$ & $3266(83.4)$ & $889(82.7)$ & \\
\hline \multicolumn{5}{|l|}{ Parent marital status $(\mathrm{n}=5030)$} \\
\hline Married & $3518(69.9)$ & $2750(69.5)$ & $768(71.4)$ & \multirow[t]{2}{*}{.226} \\
\hline Unmarried & $1512(30.1)$ & $1205(30.5)$ & $307(28.6)$ & \\
\hline \multicolumn{5}{|l|}{ Child overall health $(\mathrm{n}=5027)$} \\
\hline Fair/poor & $171(3.4)$ & $128(3.2)$ & $43(4.0)$ & \multirow[t]{4}{*}{.169} \\
\hline Good & $733(14.6)$ & $571(14.5)$ & $162(15.1)$ & \\
\hline Very good & $1976(39.3)$ & $1535(38.9)$ & $441(41.0)$ & \\
\hline Excellent & $2147(42.7)$ & $1717(43.5)$ & $430(40.0)$ & \\
\hline \multicolumn{5}{|l|}{ Child age category $(\mathrm{n}=5017)$} \\
\hline 0.0 to 5.9 years & $2487(49.6)$ & $2004(50.9)$ & $483(44.8)$ & \multirow[t]{3}{*}{.001} \\
\hline 6.0 to 12.9 years & $1767(35.2)$ & $1364(34.6)$ & $403(37.4)$ & \\
\hline 13.0 to 17.9 years & $763(15.2)$ & $572(14.5)$ & $191(17.7)$ & \\
\hline \multicolumn{5}{|l|}{ Child gender $(n=5005)$} \\
\hline Female & $2370(47.4)$ & $1879(47.8)$ & $491(45.7)$ & \multirow[t]{2}{*}{.214} \\
\hline Male & $2635(52.6)$ & $2051(52.2)$ & $584(54.3)$ & \\
\hline \multicolumn{5}{|l|}{ Child insurance $(\mathrm{n}=5019)$} \\
\hline Private & $2950(58.8)$ & $2307(58.4)$ & $643(60.0)$ & \multirow[t]{2}{*}{.345} \\
\hline Public & $2069(41.2)$ & $1641(41.6)$ & $428(40.0)$ & \\
\hline & Mean (SD) & Mean (SD) & Mean (SD) & $P$ Value \\
\hline Parent age (years) $(\mathrm{n}=4982)$ & $34.5(8.1)$ & $34.2(8.1)$ & $35.6(8.1)$ & $<.001$ \\
\hline
\end{tabular}

AA, Associate of Arts; ACA, Affordable Care Act; SD, standard deviation.

compare getting medical care for their child at the time of the survey compared with 3 years ago, $17.3 \%$ of all study parents indicated that it is harder now. When asked if their child's health had suffered because they could not afford to pay for medical care, $5.8 \%$ of all study parents answered "yes" (Table 3 ).

Almost one half of children for whom it was harder to get medical care were underinsured. Finally, $86 \%$ of parents who reported that their child's health had suffered due to not being able to afford medical care even though their child had health insurance reported their child was underinsured. On the other hand, only $12 \%$ of children whose health had NOT suffered due to parents' inability to afford needed health care were underinsured $(P<.001)$.

\section{Discussion}

This study expands an earlier study, pre-ACA, which found that about 1 in 6 children in a sample from southwestern Ohio were underinsured. ${ }^{16}$ The present 
Table 2. Risk Factors for Childhood Underinsurance

\begin{tabular}{|c|c|c|c|c|}
\hline Variable/Level & Unadjusted OR (95\% CI) & $P$ Value & Adjusted* OR (95\% CI) & $P$ Value \\
\hline \multicolumn{5}{|l|}{ Time period } \\
\hline Pre-ACA & $1.18(0.98-1.43)$ & .086 & $1.10(0.90-1.34)$ & .340 \\
\hline Post-ACA & Reference & & Reference & \\
\hline \multicolumn{5}{|l|}{ Parent } \\
\hline Mother & $2.04(1.56-2.70)$ & $<.001$ & $1.93(1.46-2.55)$ & $<.001$ \\
\hline Father & Reference & & Reference & \\
\hline \multicolumn{5}{|l|}{ Parent education } \\
\hline$\leq \mathrm{AA} /$ some college & $1.69(1.42-2.00)$ & $<.001$ & $1.30(1.06-1.60)$ & .011 \\
\hline$\geq$ College grad & Reference & & Reference & \\
\hline \multicolumn{5}{|l|}{ Household income } \\
\hline$<\$ 50,000$ & $1.98(1.69-2.32)$ & $<.001$ & $2.71(2.15-3.40)$ & $<.001$ \\
\hline$\geq \$ 50,000$ & Reference & & Reference & \\
\hline \multicolumn{5}{|l|}{ Parent race } \\
\hline Black/other & $1.33(1.09-1.61)$ & .004 & $1.19(0.97-1.47)$ & .095 \\
\hline White & Reference & & Reference & \\
\hline \multicolumn{5}{|l|}{ Parent marital status } \\
\hline Married & $0.84(0.71-0.98)$ & .032 & $1.19(0.99-1.44)$ & .071 \\
\hline Unmarried & Reference & & Reference & \\
\hline \multicolumn{5}{|l|}{ Child overall health } \\
\hline Fair/poor & $4.17(2.96-5.88)$ & $<.001$ & $3.71(2.61-5.29)$ & $<.001$ \\
\hline Good & $2.21(1.78-2.75)$ & $<.001$ & $1.97(1.58-2.47)$ & $<.001$ \\
\hline Very good & $1.35(1.13-1.62)$ & .001 & $1.28(1.07-1.54)$ & .008 \\
\hline Excellent & Reference & & Reference & \\
\hline \multicolumn{5}{|l|}{ Child age category } \\
\hline 0.0 to 5.9 years & $0.86(0.69-1.08)$ & .207 & $0.82(0.62-1.09)$ & .174 \\
\hline 6.0 to 12.9 years & $1.16(0.92-1.46)$ & .206 & $1.13(0.88-1.45)$ & .337 \\
\hline 13.0 to 17.9 years & Reference & & Reference & \\
\hline \multicolumn{5}{|l|}{ Child insurance } \\
\hline Private & $0.95(0.81-1.11)$ & .522 & $2.19(1.78-2.69)$ & $<.001$ \\
\hline Public & Reference & & Reference & \\
\hline Parent age (years) & $1.00(0.99-1.01)$ & .114 & $1.00(0.98-1.01)$ & .598 \\
\hline
\end{tabular}

* Odds ratios are adjusted for all other variables in the model; $\mathrm{n}=4802$. For child age category, the unadjusted odds ratio for 6.0 to 12.9 years compared with 0.0 to 5.9 years was $1.34 ; 95 \% \mathrm{CI}, 1.14-1.59 ; \mathrm{P}=.001$, and the adjusted odds ratio was 1.38 ; $95 \% \mathrm{CI}$, $1.13-1.68 ; \mathrm{P}=.001$.

AA, Associate of Arts; ACA, Affordable Care Act; OR, odds ratio; CI, confidence interval.

study aimed to address the status of childhood underinsurance-its prevalence and correlates-pre- and post-ACA. The national rate of uninsured children has declined post-ACA except in 2018 when the rate of uninsured children increased slightly. ${ }^{17}$ On the other hand, the rate of childhood underinsurance in southwestern Ohio did not change significantly pre/ post-ACA. Factors independently related to childhood underinsurance in this study included: parent education and/or income (lower education and/or income related to higher rates of childhood underinsurance), type of health insurance (private insurance related to higher rates of childhood underinsurance), and index child's health (children with poorer health were more likely to be underinsured). Pre- and postACA, about one third of parents of underinsured children reported their child's health had suffered due to their inability to pay for their child's health care and about 1 in 6 parents of children with health insurance pre- and post-ACA reported that they had difficulty obtaining medical care recommended by their children's clinician in the past year due to inability to pay for the recommended service.

Previous research in adults and the present study of children suggest that individuals from all age groups who are classified as "insured" have difficulty accessing the medical care they need. The findings from this study are similar to those from 2010 


\begin{tabular}{|c|c|c|c|c|}
\hline Study Outcome Measures & $\begin{array}{l}\text { All Parents } \\
\text { No. }(\%)\end{array}$ & $\begin{array}{l}\text { Pre-ACA } \\
\text { No. }(\%)\end{array}$ & $\begin{array}{l}\text { Post-ACA } \\
\text { No. }(\%)\end{array}$ & $P$ Value \\
\hline \multicolumn{5}{|l|}{$\begin{array}{l}\text { During the past } 12 \text { months, you/your child were } \\
\text { unable to: }\end{array}$} \\
\hline See a specialist to whom referred & $225(4.5)$ & $180(4.6)$ & $45(4.2)$ & .597 \\
\hline Have a recommended test done & $171(3.4)$ & $138(3.5)$ & $33(3.1)$ & .502 \\
\hline Fill a recommended prescription & $394(7.9)$ & $319(8.1)$ & $75(7.0)$ & .237 \\
\hline Obtain other medical care needed & $194(3.9)$ & $160(4.1)$ & $34(3.2)$ & .181 \\
\hline Make/keep appointment with regular doctor & $263(5.2)$ & $230(5.8)$ & $33(3.1)$ & $<.001$ \\
\hline \multicolumn{5}{|l|}{$\begin{array}{l}\text { Compared with } 3 \text { years ago, obtaining child's } \\
\text { medical care is: }\end{array}$} \\
\hline Harder & $776(17.3)$ & $607(17.5)$ & $169(16.8)$ & .658 \\
\hline The same & $3428(76.6)$ & $2661(76.6)$ & $767(76.5)$ & \\
\hline Easier & $274(6.1)$ & $207(6.0)$ & $67(6.7)$ & $<.001$ \\
\hline $\begin{array}{l}\text { During the past } 12 \text { months, child's health has } \\
\text { suffered because of not being able to afford } \\
\text { the cost of any needed care }\end{array}$ & $290(5.8)$ & $239(6.1)$ & $51(4.7)$ & .101 \\
\hline
\end{tabular}

ACA, Affordable Care Act.

publication by Kogan et al, ${ }^{5}$ which utilized the 2007 National Survey of Children's Health. In both that study and this study, parents of children with good, fair, or poor health status were more likely to be underinsured compared with children with very good or excellent health. Two recent studies of adults suggest that the ACA has reduced some racial/ ethnic disparities ${ }^{18}$ as well as health insurance disparities for disabled adults; ${ }^{19}$ but an earlier article asserts that underinsurance among children with special health care needs is the "next major challenge for child health advocates." 20

Kogan et $\mathrm{al}^{5}$ found, in a national sample, that children with special health care needs and public insurance were less likely to be underinsured than children with special health care needs and private insurance. The investigators for this study documented a similar finding for children with good/ fair/poor health (ie, fewer financial barriers with public insurance compared with private insurance) but the difference did not reach statistical significance. This suggests that a timely issue for child health advocacy may be adequate private insurance for children with special health care needs.

Of course, childhood underinsurance is a significant burden for many parents. About one third of parents of underinsured children believed that their children's health had suffered as a direct result of the family's inability to pay for recommended medical care compared with only $1.2 \%$ of parents whose children were NOT underinsured. The investigators speculate that most parents are more likely to pay for their children's needs before their own needs. This may explain, in part, the difference in the rates of underinsured adults in the Colorado and New Mexico studies (about $30 \%$ to $40 \%$ ) and the rate of 1 in 6 children underinsured in this southwestern Ohio study.

In this sample, the subgroup of families with the highest rate of underinsurance for their children reported annual incomes between $\$ 15,000$ and $\$ 34,999$, especially for families with private insurance. Similar to findings in the Kogan et $\mathrm{al}^{5}$ study, families with annual incomes below $\$ 15,000$ were more likely to have public insurance and reported lower rates of underinsurance for their children. The investigators speculate that lower income families with private insurance struggle to pay their deductibles and copays that are mandatory for their families' health insurance and therefore can afford less optimal care compared with either families with higher income and private insurance or families with lower income and public insurance.

This study has several limitations. It is a cross-sectional survey study of a compilation of samples, typically gathered between July and September or October of study years and therefore has the usual caveats regarding causality. Study parents were visiting their child's pediatrician and agreed to participate. The investigators note that the study respondents reported similar demographic characteristics to the most recent (2009) census estimates ${ }^{21}$ except this study over sampled indigent and African-American families. 
Because this is a study performed in primary care offices it does not include families in the community who were NOT seeking health care for their children due to inadequate health insurance (eg, high deductibles and/or copays) or no health insurance for their children. It is possible that a community-based sample would yield an even higher prevalence of underinsurance among children and more difficulties obtaining needed/recommended medical care for children. As noted in the Methods section, this study occurred in the Miami Valley of southwestern Ohio and public insurance is partially funded by states; therefore, the study findings regarding public insurance may vary among states.

This is the fifth study ${ }^{5,11,15,16}$ early in the 21 st century to report that underinsured individuals (adults or children) outnumber the uninsured; owning health insurance does NOT completely attenuate the suffering associated with the inability to pay for recommended health care. ${ }^{22}$ While the immediate expense of providing health care for family members affects individuals and their families, the ongoing and escalating cost of health care in any society is ultimately borne by all members of that society. ${ }^{23}$ Dr. James Perrin noted in his commentary on the study by Kogan et al, "the Affordable Care Act offers important opportunities to address the problem of underinsurance." ${ }^{24}$ Unfortunately, while the ACA has indeed decreased childhood uninsurance in the United States, including Ohio, these data suggest that it has not had a similar effect on childhood underinsurance.

\footnotetext{
The authors wish to thank all the parents who participated in the survey, and clinicians, nurses, and medical staff at the following SOAR-Net practices: Cornerstone Pediatrics, Ohio Pediatrics Inc., The Children's Medical Center of Dayton Children's Health Clinic, Rocking Horse Community Health Center, South Dayton Pediatrics, Combined Health District of Dayton, PriMed Huber Heights, Ollie Davis Center, Pediatric Associates of Dayton, Northwest Dayton Pediatrics, Primed Wright Dunbar, and University Medicine/Pediatrics.
}

To see this article online, please go to: http://jabfm.org/content/ 34/1/208.full.

\section{References}

1. Szilagyi PG, Schuster MA, Cheng TL. The scientific evidence for child health insurance. Acad Peds 2009;9:4-6.

2. Bruner C. From child health coverage to health child development: federal health reform opportunities to improve the health of America's youngest children. J Pediatrics 2010;157:1-2.
3. Mach A, Blumenthal L. Current Population Reports. Health insurance coverage of children under age 19: 2008 and 2009. U.S. Census Bureau, Current Population Reports. Washington, DC: U.S. Government Printing Office; 2010.

4. Terlizzi EP, Cohen RA, Martinez ME. Health insurance coverage: early release of estimates from the National Health Interview Survey, January-September 2018. Washington, DC: U.S. Department of Health and Human Services, Centers for Disease Control and Prevention, National Center for Health Statistics; February 2019.

5. Kogan MD, Newacheck PW, Blumberg SJ, et al. Underinsurance among children in the United States. N Engl J Med 2010;363:841-51.

6. Silverman RD. Access to care: who pays for health care for the uninsured and underinsured? J Leg Med 2008;29:1-9.

7. Schoen C, Doty MM, Robertson RH, Collins SR. Affordable Care Act reforms could reduce the number of underinsured US adults by 70 percent. Health Aff (Millwood) 2011;30:1762-71.

8. Collins SR, Bhupal HK, Doty MM. Health insurance coverage eight years after the ACA: fewer uninsured Americans and shorter coverage gaps, but more underinsured. 2019. Available from: https://www.common wealthfund.org/publications/issue-briefs/2019/feb/ health-insurance-coverage-eight-years-after-aca.

9. Oswald DP, Bodurtha JN, Willis JH, Moore MB. Underinsurance and key health outcomes for children with special health care needs. Pediatrics 2007;119:e341-7.

10. Bashshur R, Smith DG, Stiles RA. Defining underinsurance: a conceptual framework for policy and empirical analysis. Med Care Rev 1993;50:199-218.

11. Voorhees K, Fernald DH, Emsermann C, et al. Underinsurance in primary care: a report from the State Networks of Colorado ambulatory practices and partners (SNOCAP). J Am Board Fam Med 2008;21:309-16.

12. Kogan MD, Blumberg SJ, Ghandour RM, Newacheck $\mathrm{P}$, Singh GK, Strickland B. Underinsurance among children in the United States and its association with health care access and quality. Poster presented at 137th Annual American Public Health Association meeting, November 10, 2009; Philadelphia, PA.

13. Committee on Adolescence and Committee on Child Health Financing. Underinsurance of adolescents: recommendations for improved coverage of preventive, reproductive, and behavioral health care services. Pediatrics 2009;123:191-6.

14. Kogan MD, Newacheck PW, Honberg L, Stric-kland B. Association between underinsurance and access to care among children with special health care needs in the United States. Pediatrics 2005;116:1162-9.

15. Cardinali G, Rhyne RL, Fleg A, et al. Underinsurance before the implementation of the Affordable 
Care Act: from the Research Involving Outpatient Settings Network (RIOS Net). J Am Board Fam Med 2014;27:855-7.

16. Spears W, Pascoe J, Khamis H, McNicholas CI, Eberhart G. Parents' perspectives on their children's health insurance: plight of the underinsured. J Pediatr 2013;162:403-8.

17. US Census Bureau. Income, poverty and health insurance coverage in the United States: 2018. Release Number CB19-141: September 10, 2019. Available from: https://census.gov/newsroom/press-releases/2019 /income-poverty.html. Accessed September 13, 2019.

18. Chaudry A, Jackson A, Glied SA. Did the Affordable Care Act reduce racial and ethnic disparities in health insurance coverage? 2019. Available from: https://www. commonwealthfund.org/publications/issue-briefs/2019/ aug/did-ACA-reduce-racial-ethnic-disparities-coverage.
19. Kaye HS. Disability-related disparities in access to health care before (2008-2010) and after (20152017) the Affordable Care Act. Am J Public Health 2019;109:1015-21.

20. Davis MM. Medicaid, underinsurance, and the dawn of an era for children's coverage. Pediatrics 2010;125:817-9.

21. US Census Bureau. State \& county quickfacts: Montgomery County, OH. 2010. Available from: http://quickfacts.census.gov. Accessed May 25, 2011.

22. Hoffman C, Rowland D, Hamel EC. Medical debt and access to health care. Washington, DC: Kaiser Commission on Medicaid and the Uninsured; 2005.

23. Orentilcher D. Health care reform: beyond ideology. JAMA 2009;301:1816-8.

24. Perrin JM. Treating underinsurance. N Engl J Med 2010;363:881-3. 